\title{
Inovaç̃̃o econômica: trajetórias e contribuicõões de uma agenda de pesquisa sociológica
}

RAMELLA, Francesco. Sociologia dell'innovazione economica. Bologna: Ed. Mulino, 2013, 260 p.

\section{Rodrigo Foresta Wolffenbuttel*}

\section{Resumo}

A presente resenha explora os principais aspectos da obra Sociologia dell'innovazione economica do sociólogo italiano Francesco Ramella. Dividido em sete capítulos voltados para dimensões específicas da inovação, o livro apresenta as mais importantes contribuições da sociologia para o campo de pesquisa dos Innovation Studies. Para tanto, a obra recupera as contribuições sociológicas desde os clássicos da disciplina, até pesquisas atuais sobre o tema, de forma a definir o conceito de inovação e justificar a relevância da abordagem sociológica para o campo específico, mas também para a teoria sociológica em geral.

Palavras-chave: Inovação Econômica. Sociologia Econômica, Francesco Ramella.

*Universidade Federal do Rio Grande do Sul. Porto Alegre, RS, Brasil 
Economic innovation: trajectory of and contributions from a sociological research agenda

\section{Abstract}

This review explores the main aspects of Sociologia dell'Innovazione Economica by the Italian sociologist Francesco Ramella. Divided into 7 chapters, focused on particular dimensions of innovation, the book presents the main contributions of sociology to the innovation studies. To this end, the work brings the sociological contributions from the classics of the discipline to current research on the subject, in order to define the concept of innovation and justify the relevance of the sociological approach this particular field, but also to the social theory in general.

Keywords: Economic Innovation, Economic Sociology, Francesco Ramella.

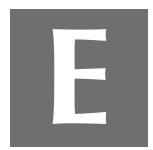

struturado na forma de manual, com resumo de conteúdo e percurso de autoverificação a cada capítulo, o livro do sociólogo italiano Francesco Ramella apresenta uma visão panorâmica das principais teorias e pesquisas sociológicas sobre o tema da inovação econômica. Tema este que vem adquirindo grande relevância no debate sobre políticas públicas e no ambiente acadêmico (Fagerberg; Verpagen 2009), configurando, dessa maneira, um campo de pesquisa emergente. Composto por uma multiplicidade de pequenos grupos de pesquisa em diversos países, ligados a uma ampla comunidade científica, este campo caracteriza-se por um enfoque cognitivo compartilhado e por um conjunto de referências comuns sobre inovação econômica. Porém, devido ao caráter essencialmente limítrofe e multifacetado do tema, os Innovation Studies tendem a extrapolar as fronteiras das disciplinas acadêmicas tradicionais, abarcando uma série de contribuições de diversas áreas do conhecimento científico, tais como a economia, engenharias, geografia, administração e sociologia.

Apesar deste caráter multidisciplinar dos Innovation Studies, Ramella destaca o recente papel desempenhado pelas ciências econômicas na construção do campo e a ausência de algo análogo por parte da sociologia. 
Ausência esta que não se justifica por falta de contribuições sociológicas seminais, uma vez que - e esse é um dos principais argumentos do livro existe uma longa tradição de estudos sociológicos que abordam o tema da inovação econômica.

Ainda que, por vezes, esta contribuição não ocorra de forma explícita, grande parte dos autores clássicos, ao abordar as mudanças sociais e o capitalismo, já apresenta uma perspectiva particular sobre o dinamismo da sociedade moderna e sua ligação com a introdução de inovações nos modos de produção e consumo. Portanto, a sociologia possui uma extensa e ampla contribuição para os Innovation Studies, pois tem como tradição abordar a inovação não apenas como um processo econômico de mudança tecnológica, mas como um processo social, intimamente vinculado ao modo de produção capitalista e a fatores institucionais e relacionais.

Com base nesta potencial contribuição, o livro busca recuperar a trajetória dos estudos sociológicos sobre inovação econômica e afirmar a relevância de uma perspectiva que não se deixa aprisionar no interior de movimentos exclusivamente utilitários. Isto é, uma perspectiva capaz de abarcar escolhas operadas em condições de profunda incerteza - pouco apropriadas ao cálculo probabilístico e maximizante dos atores atomizados - e motivações enraizadas em contextos institucionais e culturais específicos, orientadas por lógicas de interação em que a confiança e a cooperação se misturam com as usuais transações de mercado. Com isto, o livro busca ressaltar o pioneirismo e a relevância dos estudos sociológicos para os Innovation Studies e fornecer uma fonte sistemática de teorias, pesquisas e conceitos para futuras investigações.

Antes de iniciar este percurso, Ramella volta-se para a definição do conceito de inovação. Uma primeira definição literal do conceito descreve uma mudança em um estado de coisas existente, a partir da introdução de algum elemento novo. Logo, o ato de inovar implica numa relação diacrônica entre um estado de coisas anterior e um estado modificado por esse elemento novo. A partir dessa definição basilar, percebe-se o caráter necessariamente processual e relacional da inovação, isto é, trata-se de um movimento que 
compreende uma sequência de atividades interconectadas que resultam num estado de novidade em relação a um período anterior. Contudo, essa é uma definição demasiadamente ampla do conceito, que acaba por esvaziá-lo e permite uma série de confusões e inexatidões em seu emprego.

Visando a um uso mais preciso do conceito, Ramella propõe cinco pontos de esclarecimento para o debate sobre inovação: 1. Inovação é processual, trata-se de uma atividade complexa que compreende uma série de fenômenos interconectados, porém, não é necessariamente linear, com fluxo e direção estáveis no tempo; 2 . Inovação é relacional, é relativa a um período e um contexto, ou seja, só pode ser compreendida em confronto com um estado de coisas anterior e depende da contribuição de outros sujeitos, seja na fase de criação, ou na fase de implementação; 3 . Inovação é diferente de mudança, esta última é mais ampla e não necessariamente envolve algo de novo, ao contrário da inovação que implica sempre uma novidade (fazer coisas novas, ou fazer coisas que já estão sendo feitas de uma maneira nova); 4. Inovação é diferente de invenção, invenção significa conceber um novo produto ou processo, inovar implica em colocar em prática pela primeira vez esta nova ideia (enquanto a primeira permanece confinada no âmbito da elaboração, a inovação envolve as consequências de sua implementação); 5. Inovação não é necessariamente positiva, diferentemente da noção de progresso, a introdução de uma novidade nem sempre leva aos êxitos esperados - devido às consequências impremeditadas, a inovação pode falhar ou não ser benéfica para o inovador ou para a comunidade de referência.

Estes pontos de esclarecimento servem para delimitar e distinguir inovação de outros fenômenos similares e correlacionados, como invenção, mudança ou progresso. Porém, tendo em vista que a obra é intitulada "Sociologia da Inovação Econômica", cabe ainda uma ulterior delimitação em relação ao adjetivo "econômica". Neste caso, a especificidade do conceito repousa sobre um novo estado de coisas, vinculado às relações econômicas substantivas. Isto é, a inovação econômica pode ser entendida como um processo institucionalizado de mudança, que introduz elementos 
de novidade econômica: nas necessidades que venham satisfazer, nos bens e serviços que venham a produzir, ou nos modos de produção, distribuição e de uso. Diferente da concepção formal de economia, que assume o mercado abstrato como única forma de distribuição, esta definição é baseada nos sistemas econômicos concretos, processos históricos de interação entre as pessoas e seus ambientes na produção, distribuição e consumo de meios materiais para a satisfação de necessidades (Polanyi, 1980).

Dessa forma, a concepção de inovação econômica permite deslocar o foco, quase exclusivo, da inovação tecnológica, centrada na produção e na busca de soluções tecnológicas, para inserir a noção de inovação como um processo retroativo de introdução de novos produtos, novos conhecimentos, ou novos processos produtivos, no interior de um contexto. Logo, trata-se de um processo relacionado a um meio, em que a aplicação dessa novidade traz consequências econômicas para esse meio, portanto, espera-se que o meio também exerça alguma influência nessa relação, criando não apenas novos espaços para a inovação, mas também novos vetores para a novidade.

Esta leitura da inovação econômica permite concebê-la como um processo social complexo, que pode ser influenciado tanto por arranjos de políticas públicas que visam incentivar a colaboração e o desenvolvimento de determinadas inovações, quanto por impedimentos jurídicos, políticos e culturais capazes de obstruí-la (Trigilia, 2007). Contudo, muitos dos elementos dessa definição de inovação, assim como os debates subsequentes sobre o tema, são tributários de contribuições realizadas pelos autores clássicos da Sociologia.

Ramella inicia a recuperação dessas contribuições com as posições de Marx e Durkheim em relação ao debate inaugurado por Adam Smith sobre a divisão do trabalho. A principal discordância entre o economista escocês e os clássicos da sociologia fica por conta dos seus entendimentos sobre as consequências da divisão do trabalho para a sociedade moderna. Enquanto Smith percebe a divisão do trabalho como uma fonte de riqueza e aumento da produtividade - graças ao aumento da destreza dos trabalhadores 
especializados, redução do tempo de trabalho necessário e invenção de novas máquinas específicas para determinadas funções - Marx e Durkheim opõem-se a essa perspectiva positiva e necessária da divisão do trabalho.

A contribuição de Marx para o debate sobre inovação está centrada nos seus estudos sobre a dinâmica transformadora do capitalismo. Numa das mais famosas passagens do Manifesto Comunista, Marx e Engels descrevem como condição de existência da burguesia o imperativo de revolucionar incessantemente os instrumentos de produção e, com isso, todas as relações sociais. Este aspecto revolucionário não estaria vinculado apenas à necessidade de produção de valor excedente, baseada na exploração da força de trabalho e no aumento da capacidade produtiva, mas à dinâmica concorrencial e expansionista do próprio sistema capitalista. O que faz da inovação econômica e do progresso científico elementos centrais nesta disputa e, consequentemente, na transformação dos meios de produção e das relações sociais.

Em relação à divisão do trabalho e à divisão técnica na indústria, Marx ressalta o caráter contraditório e conflituoso de sua aplicação no modo de produção capitalista. A divisão especializada do trabalho capitalista provoca um processo de desqualificação radical dos produtores não possuidores dos meios de produção (artesãos, trabalhadores), o que gera alienação e dificulta o desenvolvimento de sua capacidade criativa. Para Marx, de fato, a superação do capitalismo exigiria também a superação da divisão do trabalho, especialmente a do trabalho manual e intelectual. Além disso, a aplicação da ciência ao processo produtivo capitalista, no contexto das grandes fábricas mecanizadas, teria transformado o operário em um insignificante apêndice das máquinas.

A partir dessas considerações, torna-se clara a posição de Marx sobre as consequências da divisão do trabalho e da implementação de novos aparatos tecnológicos no processo produtivo capitalista. Longe de uma concepção neutra, ou positiva, Marx ressalta a dimensão conflituosa da inovação tecnológica e econômica, pois tratam-se de processos que 
comportam tensão e se enquadram no interior de relações de poder que tendem a desencadear dinâmicas de conflito.

Durkheim, por seu turno, entende a divisão do trabalho como algo não necessariamente positivo, mas como um fenômeno que pode produzir efeitos benéficos para a coesão social, quando associado à solidariedade e à justiça social. Apesar de reconhecer que a divisão do trabalho aumenta o desempenho do trabalho, proporcionando mais recursos e melhor qualidade, Durkheim discorda da visão utilitarista que entende a origem da divisão do trabalho a partir do desejo humano de aumentar constantemente seu bem-estar material e sua própria felicidade. Diretamente vinculada ao grau de uniformidade da consciência coletiva, ainda que o desenvolvimento da divisão do trabalho social favoreça o surgimento de iniciativas e padrões de comportamento individuais, ela gera uma forma de cooperação baseada na troca e em normas de reciprocidade, que se exprimem através dos contratos e pressupõe uma relação normativa, não apenas de tipo jurídico, mas também moral.

Portanto, a simples divisão e especialização do trabalho não é garantia de coesão social. Seu principal efeito não seria aumentar o rendimento das funções divididas, mas produzir solidariedade. Quando há ausência dessas normas jurídicas e morais, a divisão do trabalho tende a agir de maneira dissolvente na sociedade. Nesse sentido, para tornar solidárias as funções segmentadas, a divisão do trabalho deve associar-se a uma adequada qualificação, coordenação e motivação dos trabalhadores, a fim de evitar que a progressiva redução dos intercâmbios e contatos os isole, a ponto de perderem de vista a dimensão comum e colaborativa do seu trabalho. Do contrário, os resultados tendem a produzir as sucessivas crises que perturbam periodicamente as funções econômicas.

Esta ideia pode ser extrapolada para uma correlação entre divisão do trabalho e inovação. Para que a divisão aumente a colaboração e, potencialmente, a capacidade inovadora dos trabalhadores, é necessário que o trabalho não seja excessivamente empobrecido e que exista também um envolvimento subjetivo em relação às metas do trabalho e com o 
grupo de trabalho. Dessa forma, torna-se claro o papel da intensificação das relações sociais no estímulo à criatividade. Em outras palavras, a inovação econômica não é apenas o resultado da especialização e diferenciação das tarefas, mas requer envolvimento subjetivo, exploração e combinação de diferentes elementos e, muitas vezes, uma coordenação e um trabalho em grupo.

Logo, percebe-se que tanto Marx quanto Durkheim acreditam que, na sociedade capitalista, a divisão do trabalho não determina (necessariamente) um aumento do bem-estar individual e coletivo, pois nem todas as classes sociais se beneficiam na mesma medida (Marx) ou porque a riqueza material não coincide com a felicidade individual (Durkheim). Além disso, ambos concordam em que a especialização excessiva de trabalho tende a empobrecer ao invés de enriquecer as qualificações profissionais, reduzindo a vontade subjetiva e a capacidade de inovar dos trabalhadores. Porém, acabam-se aqui as consonâncias entre os autores em relação à divisão do trabalho e suas respostas para as questões levantadas.

Após recuperar as contribuições destes dois clássicos, voltadas principalmente para a dimensão estrutural e processual da inovação, Ramella passa a discorrer sobre as contribuições de clássicos que se concentraram no papel dos atores sociais. Tratam-se de autores que examinaram a origem histórica e social de uma nova figura, a do empreendedor, até então naturalizada pelos economistas clássicos.

Começando por Simmel e Sombart, autores que exploraram a emergência de uma nova mentalidade econômica a partir de indivíduos socialmente marginais, Ramella apresenta dois mecanismos geradores para compreensão da inovação econômica. Devido à posição periférica de alguns indivíduos e grupos sociais (imigrantes, estrangeiros, minorias étnicas e religiosas), haveria uma maior liberdade em relação às normas do grupo e uma maior possibilidade de recombinar ideias de outras experiências. Isto teria permitido que estes indivíduos promovessem o uso da moeda, a acumulação de capitais, a difusão do comércio e das trocas, como forma de se estabelecerem. Ou seja, esta posição marginal favoreceria uma mentalidade 
disposta a atuar de forma inovadora em relação aos costumes e normas, a fim de encontrar/ produzir uma posição na sociedade capitalista emergente.

Os mecanismos de inovação propostos nesta tese baseiam-se em duas dimensões vinculadas a essa dinâmica de transformação: uma normativa, em que a menor intensidade das normas sociais e culturais dos grupos comunitários possibilitaria uma maior liberdade em relação aos mecanismos de controle social (mecanismo baseado na marginalidade); e uma sociocognitiva, em que a posição entre mundos diversos possibilitaria a obtenção de informações não redundantes, colocando em contato ideias diversas que podem ser combinadas de diferentes maneiras (mecanismo baseado na intermediação).

Embora pareçam relativamente banais, estes mecanismos fundamentam grande parte da literatura sobre inovações econômicas. Diversos estudos citados ao longo do livro buscam compreender os mecanismos e as condições que favorecem a geração e a difusão de inovações. Isso envolve desde estudos sobre clusters high tech como o Silicon Valley e seu dinamismo inovador, baseado em uma rede complexa de atores heterogêneos e complementares (Ferrary; Granovetter, 2009), até pesquisas sobre a importância de conexões homogêneas locais em conjunto com conexões de longa distância, para a criatividade e inovação na indústria de musicais da Broadway (Uzzi; Spiro, 2005). São estudos que buscam, através da análise de redes sociais, estabelecer um elo entre as estruturas e os atores. Portanto, tratam-se de ideias seminais que fornecem chaves teóricas para a compreensão da inovação econômica a partir de mecanismos de interação entre atores sociais com diversas identidades e posições em um "campo".

Outra importante contribuição ao debate sobre a origem da figura do empreendedor pode ser encontrada nos estudos de Weber sobre a gênese do capitalismo moderno. Marcado pela cobertura das necessidades cotidianas por intermédio da empresa capitalista, com suas características de cálculo e administração racional, o capitalismo moderno/ocidental dependeu de diversos fatores e pré-condições (econômicos, políticos, 
culturais) para sua consolidação. A conjunção desta constelação de fatores e das afinidades entre eles originou um processo de desencantamento do mundo e racionalização de todas as esferas da vida social; isto é, uma organização racional do trabalho, do direito, da ciência e da técnica e a emergência de um éthos racional de condução da vida.

Estes pressupostos socioinstitucionais, em consonância com uma ética social legitimadora do ganho e da acumulação, enfraqueceriam o tradicionalismo econômico e possibilitariam a emergência de novas formas de conduta, produção, distribuição e consumo. Porém esta ruptura com o tradicionalismo não ocorre sem as resistências das formas estabelecidas e, por isso, depende de um tipo específico de caráter e carisma, capaz de escapar às tradições recebidas.

Ao tratar dos diversos fatores implicados no surgimento do capitalismo moderno, Weber oferece duas leituras, intimamente correlacionadas, sobre a formação do empreendedorismo capitalista. A primeira, do tipo macro, sublinha a importância de um conjunto de fatores institucionais, sociais e culturais para a criação de um éthos profissional-racional que impulsiona comportamentos inovadores que rompem com o tradicionalismo econômico. A segunda, no nível "micro", chama a atenção para um mecanismo carismático de inovação: isto é, as qualidades éticas e pessoais dos empresários puritanos que, para escapar da influência da tradição e superar a resistência à inovação, devem exercer uma função de liderança com características carismáticas. Este mecanismo parece encontrar eco em alguns recentes casos de líderes carismáticos de empresas inovadoras, como Steve Jobs e Elon Musk.

Para além dessas contribuições, Weber exerceu uma forte influência sobre a obra de um dos principais economistas da inovação. Colaborador de Weber e coeditor da revista Archiv für Sozialwissenschaft und Sozialpolitik, Joseph Schumpeter foi responsável pela inserção da inovação no centro do debate sobre o desenvolvimento capitalista. A partir do seu entendimento socio-histórico da economia, Schumpeter pôde formular uma contundente crítica ao modelo neoclássico de economia, 
que entendia a mudança tecnológica como algo dependente de fatores externos ao sistema econômico, e estabelecer uma diferença entre crescimento e desenvolvimento econômico. Enquanto o crescimento é contínuo, incremental e ocorre sem necessariamente modificar o quadro das condições dadas, o desenvolvimento pressupõe uma descontinuidade, uma mudança no modo tradicional de realizar as coisas.

Para o economista heterodoxo, o capitalismo possui um caráter essencialmente dinâmico, dependente de fatores endógenos ao próprio capitalismo. Tratam-se de mudanças tecnológicas e organizativas que revolucionam incessantemente a estrutura econômica por dentro, destruindo o antigo, incessantemente, e criando o novo, incessantemente. É esse processo de "destruição criativa" que caracteriza o capitalismo. Logo, o motor do desenvolvimento capitalista é a inovação.

Ainda que Schumpeter vincule esta capacidade de realizar coisas novas a fatores psicológicos, ligados à personalidade individual do empreendedor inovador, isto não quer dizer que a inovação é fruto exclusivo da vontade do empreendedor. Antes, ele a relaciona também ao contexto socioinstitucional em que se insere, inclusive estabelecendo diferenças entre o modelo de capitalismo concorrencial - no qual a inovação era introduzida por novos homens que dirigiam pessoalmente e eram proprietários de novas empresas - e o capitalismo monopolista - em que a inovação é fruto de pesquisas e laboratórios de grandes empresas oligopolistas. Assim como em Weber, esta dupla dimensão do processo aponta para a complexidade do fenômeno, dependente de níveis de análise diferentes, mas correlacionados - agentes com características específicas vinculados a contextos socioinstitucionais históricos.

Todas essas contribuições fundamentaram estudos subsequentes, principalmente na Sociologia Econômica, sobre inovação. Por exemplo, a importância do contexto socioinstitucional (tradição "macro") para a inovação foi revitalizada por estudos comparativos de economia política sobre modelos de capitalismo (Hall; Soskice, 2001). Já o papel de fatores sociorrelacionais (mecanismos "micro") encontrou espaço nas reflexões 
da abordagem estrutural das redes de interação (Schilling; Phelps, 2007; Uzzi; Spiro, 2005). Por fim, há aqueles, como Ramella, que percebem os Innovation Studies como uma oportunidade para desenvolver um diálogo integrado entre ambas as abordagens.

Muitos desses estudos são extensamente apresentados e comentados no livro, porém, devido à complexidade dos processos inovadores e das dinâmicas de interação que envolvem uma pluralidade de atores e instituições (inclusive não econômicos), Ramella optou por separá-los, com base em suas ênfases sobre as dimensões da inovação. Isto é, estudos que enfatizam o papel da criatividade e dos atores envolvidos no processo; as relações inovadoras e as formas de interação, em redes, principalmente; e contextos onde ocorrem as inovações, como os sistemas nacionais, regionais e locais.

Cabe registrar a ausência das contribuições dos "estudos sociais em ciência e tecnologia" no livro. Embora não lidem diretamente com inovação econômica, há importantes pesquisas sobre mudança tecnológica e processos científicos que contribuem para o debate sobre o tema, principalmente em relação à pluralidade de interesses em jogo durante o processo inovador e à necessidade de negociação destes interesses, naquilo que os autores denominam de processos de tradução (Akrich; Callon; Latour, 2002).

Apesar da afluência das contribuições trazidas no livro, grande parte da discussão atual sobre inovação parece esterilizada, presa à esfera da economia formal e aos sentidos mais rasos. Pois, mesmo que a importância dos aspectos institucionais e sociorrelacionais seja reconhecida, algumas das mencionadas dimensões constitutivas dos processos de inovação (poder, conflito e legitimação) ficam negligenciadas, e o mesmo ocorre em relação à sua interdependência com as mudanças sociais.

Tendo isso em vista, Ramella reafirma a potencial contribuição da sociologia para o tema e procura ofertar uma abordagem de estudos integrada sobre inovação, capaz de abranger as múltiplas dimensões de análise, sua íntima vinculação com a mudança social e as dinâmicas de contestação/aceitação inerentes ao processo. Em outras palavras, inovação como um complexo processo relacional e multidimensional que depende, 
em grande medida, dos atores sociais, das dinâmicas de interação e do contexto social em que se desenrola o ato inovador.

Além de reivindicar para a sociologia uma posição de relevo no debate sobre o tema, essa proposição recupera o aspecto social da inovação. Ao complexificar o conceito, inserindo contingência, disputa, poder e contradição na equação, Ramella questiona os sentidos amplamente difundidos e naturalizados de inovação, como algo necessariamente positivo, vinculado ao progresso e oposto a estruturas arcaicas. E, ao fazer isso, desloca o fenômeno, que passa a ser lido em conexão com o sistema econômico concreto em que se insere e com as dinâmicas de interesse envolvidas no processo.

Em resumo, trata-se de uma referência obrigatória para aqueles que se interessam por processos de mudança tecnológica e social vinculados à inovação econômica, em especial sob a perspectiva da Sociologia Econômica. Não apenas por apresentar o estado da arte das pesquisas sob o tema e propor uma consequente abordagem de estudos integrados de inovação, mas também por fornecer uma vasta agenda de pesquisa e levantar questões relativas à teoria sociológica mais geral.

Rodrigo Foresta Wolffenbuttel é Mestre em Sociologia e Doutorando no Programa de PósGraduação em Sociologia da Universidade Federal do Rio Grande do Sul.

$\risingdotseq$ rodrigoforesta@gmail.com

\section{Referências}

1. AKRICH, Madeleine; CALLON, Michel; LATOUR, Bruno. The Key to Success in Innovation Part I and II: the Art of Interessement. International Journal of Innovation Management, London, v. 6, n. 2, p. 187-206, jun. 2002.

2. FAGERBERG, Jan; VERSPAGEN, Bart. Innovation Studies: The Emerging Structure of a New Scientific Field. Research Policy, v. 38, n. 2, p. 218-233, 2009.

3. FERRARY, Michel; GRANOVETTER, Mark. The Role of Venture Capital Firms in Silicon Valley's Complex Innovation Network. Economy and Society, v. 38, n. 2, p. 326-359, 2009. 
4. HALL, Peter A.; SOSKICE, David. Varieties of Capitalism. The Institutional Foundations of Comparative Advantage. Oxford: Oxford University Press, 2001.

5. POLANYI, Karl. A grande transformação: as origens de nossa época. Rio de Janeiro: Campus, 1980.

6. SCHILLING, Melissa A.; PHELPS, Corey C. Interfirm Collaboration Networks: The Impact of Large- Scale Network Structure on Firm Innovation. Management Science, v. 53, n. 7, p. 1113-1126, 2007.

7. TRIGILIA, Carlo. La costruzione sociale dell'inovazione. In: La costruzione sociale dell'innovazione: economia, società e territorio. Firenze: Firenze University Press, 2007. p.11-18.

8. UZZI, Brian; SPIRO, Jarret. Collaboration and Creativity: The Small World Problem. American Journal of Sociology, v. 111, n. 2, p. 447-504, 2005. 